Bulletin d'Histoire Contemporaine de l'Espagne

$51 \mid 2017$

Les forces politiques durant la Seconde République espagnole

\title{
Un partido para acabar con los partidos: el
} fascismo español, 1931-1936

Un parti pour en finir avec les partis : le fascisme espagnol, 1931-1936

A party to end parties: spanish fascism, 1931-1936

\section{Julio Gil Pecharromán}

\section{OpenEdition}

\section{Journals}

Edición electrónica

URL: http://journals.openedition.org/bhce/673

DOI: $10.4000 /$ bhce.673

ISSN: 1968-3723

Editor

Presses Universitaires de Provence

Edición impresa

Fecha de publicación: 1 junio 2017

Paginación: 69-84

ISSN: 0987-4135

Referencia electrónica

Julio Gil Pecharromán, "Un partido para acabar con los partidos: el fascismo español, 1931-1936 », Bulletin d'Histoire Contemporaine de l'Espagne [En línea], 51 | 2017, Publicado el 09 octubre 2018, consultado el 19 abril 2019. URL : http://journals.openedition.org/bhce/673 ; DOI : 10.4000/bhce.673 


\section{Un partido para acabar con los partidos: el fascismo español, 1931-1936}

\section{Julio GIL PECHARROMÁN}

UNED

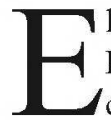
1 fascismo, entendido como ideología y como modelo de partido político, fue, en España, un movimiento tardío y débil con relación a sus homólogos europeos. Es cierto que, a partir del verano de 1936, su entonces único representante, Falange Española de las JONS, creció hasta convertirse en un partido de masas. Pero ello fue en el contexto anómalo de una guerra civil y de un proceso forzado de convergencia del fascismo primigenio con las diversas fuerzas de la Derecha en lo que se ha denominado la "coalición reaccionaria» ${ }^{1}$. $Y$, en menos de un año, esa coalición se convirtió en el partido único de una dictadura que tenía en el fascismo un referente doctrinal fundamental -por lo menos hasta 1945- pero equilibrado por otros componentes como el catolicismo político, el conservadurismo autoritario o el tradicionalismo carlista.

El fascismo, como referente político, estuvo presente en la vida española prácticamente desde que se originó en la Italia de 1919. Pero su consolidación en el plano doctrinal de la Derecha española fue lenta e incompleta, y en el de la organización de partidos no cuajó hasta 1933, pese a la existencia anterior de algunos conatos de muy escaso relieve.

\section{Conatos y tanteos}

Las primeras iniciativas pre-fascistas, correspondientes a lo que se conoce genéricamente como derecha radical, respondieron a una reacción defensiva de la masa social conservadora -las «gentes de orden»- ante los ecos de la Revolución Rusa y el caos causado en Europa por el final de la Gran Guerra. Y, sobre todo, ante la presión ejercida por la izquierda obrera española a través de las movilizaciones de lo que se conoció como el Trienio Bolchevique, que tuvo su primera y más seria manifestación en la «huelga general revolucionaria» de 1917. Fue en este contexto en el que las ligas ciudadanas, o uniones civicas, arraigadas especialmente entre los sectores más conservadores y nacionalistas de la clase media urbana, vislumbraron en el fascismo una metodología de acción y una racionalización doctrinal contrarrevolucionarias que iban más allá de las meras actitudes defensivas ${ }^{2}$. Tal fue el caso de la Liga Patriótica Española, creada en Barcelona al calor del crecimiento de la presión

1 Glicerio Sanchez Recio, Sobre todos, Franco. Coalición reaccionaria y grupos politicos en el Franquismo, Barcelona, Flor del Viento, 2008, p. 32-37.

2 F. Del Rey y S. Bengoechea, «En vísperas de un golpe de Estado. Radicalización patronal e imagen del fascismo en España», en J. Tusell, J. Gil Pecharromán y F. Montero (eds.), Estudios sobre la derecha española contemporánea, Madrid, UNED, 1993, p. 301-326; E. Gonzalez CALleja y F. Del Rey, La defensa armada contra la revolución. Una historia de las «guardias civicas» en la España del siglo XX. Madrid, 1995. 
catalanista en 1918-1919, y dirigida por el carlista Ramón Sales, líder de los Sindicatos Libres. En paralelo con los Libres, la Liga se implicó en las luchas sociales a partir de la dura huelga de La Canadiense (febrero-abril de 1919). Y por entonces comenzó, también en Cataluña, a intervenir en los conflictos sociales el Somatén, una milicia local con tareas de auxilio a las fuerzas policiales en defensa del orden y de la propiedad, pero que a raíz de la huelga de La Canadiense asumió un componente político que implicaba un abierto rechazo al sistema constitucional, al que los somatenistas acusaban de debilidad intrínseca frente a las fuerzas revolucionarias del obrerismo.

También contribuyeron a crear suelo para un futuro fascismo algunas iniciativas similares en Madrid y otras ciudades, donde las Juventudes Mauristas llevaban años preparando la movilización callejera de la derecha radical. Surgieron ligas como Defensa Ciudadana y Unión Ciudadana, dispuestas a respaldar con la violencia el mantenimiento del orden público y a profundizar en la radicalización política de la derecha conservadora ${ }^{3}$. No eran iniciativas relacionadas directamente con el fascismo, por el que mostraban simpatías pero también un conocimiento muy superficial, sino más bien con el nacionalismo radical y el antiliberalismo de la konservative revolution. Contribuyeron a dotar al régimen dictatorial surgido del golpe de Estado militar de 1923, de justificaciones autoritarias y le aportaron cierta base social de activismo militante.

Hubo, sin embargo, dos conatos de partido que buscaban abiertamente identificarse con el fascismo. El impulsor del primero representó luego un papel de cierta importancia en la concreción de la opción fascista durante la República. El periodista canario Manuel Delgado Barrero, diputado y director del diario maurista madrileño La Acción, intuyó enseguida que la vía mussoliniana de conquista del Poder era factible en España si se forzaban algo las condiciones políticas para atraer a un amplio sector de las gentes de orden a «la senda de un fascismo español». A finales de 1922, mientras desde su periódico se realizaban abiertas llamadas al golpe de Estado, animando a ello incluso al rey, Delgado sacó a la calle una revista, La Camisa Negra, que sufragaban algunos empresarios vinculados al maurismo y que nacía con el propósito de facilitar la aparición de «un Mussolini español». La meta debía ser la creación de una organización política militarizada, la Legión Nacional, directamente inspirada en los fasci di combattimento, a la que se convocaría a los excombatientes de la guerra de Marruecos, descontentos con el sesgo político del conflicto y con su situación persona $1^{4}$. El intento no llegó a ninguna parte.

La segunda iniciativa tuvo lugar en Barcelona donde, en marzo de 1923, se dio a conocer un grupo denominado La Traza, de carácter básicamente anticatalanista y encuadrado por oficiales de la guarnición militar. La Traza, que no habría pasado de tres centenares de miembros, apelaba a las masas para luchar contra el sistema parlamentario utilizando un modelo organizativo paramilitar y un lenguaje adaptados del fascismo italiano. Pero no parece que la visión doctrinal de los «camisas azules» trazistas fuese más allá del regeneracionismo autoritario que compartían con los generales golpistas de septiembre de $1923^{5}$.

El establecimiento de la dictadura de Primo de Rivera representaba, en cierto modo, el triunfo de esta línea de derecha radical filo-fascista. Pero, como se demostraría reiteradamente a escala europea en el período de entreguerras, la existencia de un régimen autoritario de

3 E. González Calleja, El máuser y el sufragio. Orden público, subversión y violencia política en la crisis de la Restauración (1917-1931), Madrid, CSIC, 1999.

4 J. L. RodRiguez JIMÉNEZ, "Una unidad militar en los orígenes del fascismo en España: la Legión», en Pasado y memoria, $\mathrm{n}^{\circ}$ 5, 2006, p. 238-239.

5 J. M. Thомás, Los fascismos españoles, Barcelona, Planeta, 2011, p. $42-46$. 
regeneracionismo conservador no era el medio adecuado para el crecimiento del fascismo, que precisaba de la amenaza revolucionaria de la izquierda obrera y de un sistema democrático liberal, garantista y «decadente», para consolidarse como alternativa totalitaria.

Durante los primeros meses de la Dictadura se desató una carrera entre las diversas opciones de la derecha anti-liberal -conservadurismo autoritario, catolicismo social, tradicionalismo- por aportar componentes doctrinales y estructuras de militancia política a la nueva situación. En tales condiciones, los pre-fascistas tenían pocas opciones. El grupo de La Traza se unió a un sector radicalizado del Somatén en una Federación Cívico-Somatenista que buscaba asumir un papel de organización oficialista amparada por el Directorio. Pero la creación del Somatén Nacional, institucionalizado y puesto bajo control militar a los cuatro días del golpe de Estado, redujo su función a un activismo local en paralelo con otros grupúsculos de derecha radical, como la Peña Ibérica o el Grupo Alfonso. La Traza desapareció formalmente en 1926.

La Unión Patriótica Española (UPE), la organización de masas que Primo de Rivera asumió como base de apoyo popular a su régimen y «madre» de un nuevo sistema de partidos en un futuro de política regenerada, recogía las diversas tradiciones de la Derecha española ${ }^{6}$. De hecho, el partido había sido creado, pocas semanas después del golpe de Estado, como Unión Patriótica Castellana, por Ángel Herrera Oria, presidente de la Asociación Católica Nacional de Propagandistas (ACNP) e impulsor de un «catolicismo social» antiliberal y propugnador de un Estado confesional y corporativo de índole tradicional. Esta Unión Patriótica, ofrecida a Primo de Rivera como alternativa política al somatenismo y oficializada como partido del régimen, se convirtió en una poco operativa plataforma de masas, con eerea de un millón de adherentes, atraídos por su carácter oficialista y la promesa de promoción personal que ofrecía su proximidad al Poder. Respondía la UPE al modelo de partidos «privilegiados» que, como el polaco Bloque No Partidista de Colaboración con el Gobierno, el Frente Patriótico austríaco, o el rumano Frente del Renacimiento Nacional, buscaban integrar al conjunto de fuerzas «nacionales» en una organización al servicio del orden conservador que amparaban sus dictaduras. Por lo tanto, la vinculación doctrinal de la UPE con el fascismo era prácticamente nula, entre otras cosas porque en la Unión predominaba la «mentalidad» sobre la «ideología» ${ }^{7}$, más bien confusa esta, aunque no cabe duda sobre la abierta simpatía de una parte de su militancia hacia el régimen italiano.

En este contexto, la coyuntural aproximación diplomática a Italia, el modelo de Estado corporativo diseñado en la nonata constitución de 1929, o los proyectos de organización corporativa del ministro de Trabajo, Eduardo Aunós, que viajó a Italia para estudiar el modelo laboral fascista, podian responder a una genérica simpatía por el sistema dictatorial impulsado por Mussolini, pero no implicaban identificación con sus parámetros totalitarios y se atenían más bien a las esencias del catolicismo social de raíz tradicionalista. Y esto era especialmente claro en el caso de Primo de Rivera, que nunca comprendió lo que había tras el fascismo. En fecha tan tardía como la primavera de 1929, avalaba que su Somatén era

6 No hay, publicada, una monografía extensa sobre la UPE, aunque sí abundantes artículos. Pueden encontrarse referencias bibliográficas actualizadas en E. González CALLEJA, La dictadura de Primo de Rivera: la modernización autoritaria, Madrid, 2006.

7 J. L. Gómez-NAvarro, "La Unión Patriótica: análisis d'un partido en el poder», en Estudios de Historia Social, $\mathrm{n}^{\circ} 32-33,1985$, p.118. 
«lo que puede parecerse más a un fascismo», ya que constituía «una unión de gente honesta y armada para la defensa y el orden $\rangle^{8}$.

\section{El experimento jonsista}

La caída de la Dictadura y el proceso de vuelta a la normalidad constitucional auspiciado por el Gobierno del general Berenguer, con la convocatoria de elecciones parlamentarias a corto plazo, obligaron a recomponer el sistema de partidos de la Derecha. Perdida su posición de privilegio, la Unión Patriótica se disolvió rápidamente y el primorriverismo se refugió en un nuevo partido, de afiliación mucho menor pero mayor coherencia doctrinal, que adoptó el nombre de Unión Monárquica Nacional y lanzó una campaña en defensa de la obra del Directorio y en contra del retorno a las prácticas de la «vieja política»".

La disolución de la UPE propició, por otra parte, un reagrupamiento de la derecha radical en una serie de grupúsculos que pretendían reanudar la movilización antirrevolucionaria de las «uniones cívicas». Aunque la mayoría de ellos respondían a modelos de conservadurismo autoritario, o de neotradicionalismo -la Juventud Monárquica Independiente, el Partido Socialista Monárquico- algunos jugaban ya con elementos de proximidad al fascismo, como era el caso del Partido Laborista, de Aunós y, sobre todo, del Partido Nacionalista Español. El PNE fue fundado, en abril de 1930, por el neurólogo valenciano José María Albiñana, pero en su creación jugó un papel fundamental Delgado Barreto, que buscaba relanzar su frustrado proyecto de Legión Nacional y que puso el diario que dirigía, La Nación antiguo órgano de la UPE- al servicio del nuevo partido. Este se dotó de algunos elementos fascistizantes, como el saludo brazo en alto o, más tarde, un uniforme con camisa azul celeste y gorro legionario. Pero, sobre todo, creó la primera milicia de partido de la Derecha española, los violentos legionarios de España, «voluntariado ciudadano con intervención directa, fulminante y expeditiva en todo acto atentatorio o depresivo para el prestigio de la Patria», como los definía su fundador ${ }^{10}$. Aunque Albiñana mostraba abiertas simpatías por el fascismo, carecía de capacidades como ideólogo y tanto el carácter de sus seguidores como su propia concepción de la acción política parecen fijar como modelo del PNE las Ligas Patrióticas de la derecha radical francesa, y no el italiano Partido Nacional Fascista ${ }^{11}$.

En los años de la Dictadura se mantuvo activo un frente intelectual de difusión de las ideas fascistas, integrado por gentes de diversa procedencia ideológica a las que el inicio de la experiencia mussoliniana ofrecía «una seducción compartida» ${ }^{12}$. La recepción de esas ideas, estimulada por las autoridades culturales italianas, se producía en varios niveles, desde las disquisiciones doctrinales y filosóficas de La Gaceta Literaria, la revista vanguardista que editaba Ernesto Giménez Caballero a partir de $1927^{13}$, hasta los artículos

8 Declaraciones a Il Corriere della Sera, 19-3-1929.

9 J. Gl Pecharromán, «Un conservadurismo de transición. La Unión Monárquica Nacional» en Haciendo Historia. Homenaje al Profesor Carlos Seco Serrano, Madrid, Universidad Complutense, 1989, p. 481-492.

10 La Nación, 13-4-1930.

11 J. GL Pecharromán, «Sobre España inmortal, sólo Dios». José María Albiñana y el Partido Nacionalista Español (1930-1937), Madrid, UNED, 2000.

12 M. Pelolle, Fascismo en ciernes. España 1922-1930. Textos recuperados, Toulouse, Presses Univ. du Mirail, 2006, p. 35.

13 Entre los estudios sobre Gecé, se encuentran el clásico de D. W. FoARD, Ernesto Giménez Caballero lo la revolución del poeta), Madrid, Instituto de Estudios Políticos, 1975, y E, Selva Roca de Togores, Ernesto Giménez Caballero, entre la vanguardia y el fascismo, Valencia, Pretextos, 2000. Un ensayo 
de divulgación con trazo grueso de la prensa popular, entre la que La Nación de Delgado Barreto destacó por su entusiasmo filo-fascista. Estos esfuerzos de difusión del fascismo resultaban, no obstante, bastante dispersos y sus propagandistas tenían dificultades para adaptarlos a una realidad española en la que, a partir de septiembre de 1923, el peligro de la revolución obrera o del separatismo catalán y, por tanto, la necesidad de estimular el cortafuego fascista, habían dejado de ser percibidos como una prioridad por los sectores más radicalizados de la Derecha.

Las cosas cambiaron a lo largo de 1930 y, sobre todo, en los primeros meses de 1931. Los esfuerzos del Gobierno Berenguer por recuperar el sistema liberal-parlamentario, así como el crecimiento de la presión de las izquierdas republicana y socialista, que alcanzaron un acuerdo político e intentaron un golpe de Estado antimonárquico a mediados de diciembre, parecieron favorecer las condiciones de confrontación precisas para el cultivo de un fascismo español. Pero los pequeños partidos de derecha radical, meramente defensivos y con un grado mínimo de fascistización en el mejor de los casos, no podían asumir esa tarea.

Fue en este contexto en el que Ramiro Ledesma Ramos, un joven funcionario de Correos, intelectual que bebía de las teorías de Heiddeger, Gentile, Ortega y Gasset y Giménez Caballero, de cuya revista era colaborador, aglutinó la iniciativa de un grupo -Juan Aparicio, Giménez Caballero, Antonio Bermúdez Cañete, Emiliano Aguado, etc.- ya con el abierto objetivo de dar paso a un movimiento político de carácter fascista ${ }^{14}$. El 14 de marzo de 1931 apareció un semanario, La Conquista del Estado, cuyo manifiesto político marcaba abiertas diferencias con el lenguaje de la derecha radical. Así, afirmaba que «en todas partes se desmorona la eficacia del Estado liberal-burgués», mientras que el marxismo es «la primera visión clara del carácter de nuestra civilización industrial y técnica», pero contra el que «nosotros lucharemos», ya que sus propuestas eran inasumibles. El manifiesto, del que podía inferirse una predilección por un sistema republicano, se pronunciaba por una «soberanía del Estado, indiscutible y absoluta», que llevaría a la «extirpación de los focos regionales que den a sus aspiración un sentido de autonomía política» y proponía una economía bajo control estatal y sindical, que incluiría «la expropiación de los terratenientes». La creación del Nuevo Estado requeriría no del voto de las masas, sino de «minorías audaces y valiosas, jóvenes equipos militantes, sin hipocresía frente al fusil y la disciplina de guerra». Una organización constituida por pequeñas «células sindicales y políticas», con miembros menores de 45 años - el culto a la juventud propio de la doctrina fascista- sería la eneargada de asumir la conquista del Estado liberal-burgués y su trasformación en otro revolucionario, basado en los principios del pan-estatismo:

Al hablar de supremacía del Estado se quiere decir que el Estado es el mismo valor político y que el mayor crimen contra la civilidad sería ponerse frente al nuevo Estado. Pues civilidad -la convivencia civil- es algo que el Estado, y sólo él, hace posible. ¡¡Nada pues sobre el Estado!! ${ }^{15}$.

sobre la propaganda fascista italiana en España y el lugar de La Gaceta en ello, en V. PEÑa SáncheZ, Intelectuales y fascismo. La cultura italiana del ventennio fascista y su repercusión en España, Granada, Adhara, 1993.

14 La biografía clásica es la de T. Borrás, Ramiro Ledesma Ramos, Madrid, Editora Nacional, 1971, muy favorable al personaje. Más equilibrada es la de J. M. SÁnchez Diana, Ramiro Ledesma Ramos. Biografia politica, Madrid, Editora Nacional, 1975. Entre las recientes destaca la de F. GALLEGo, Ramiro Ledesma Ramos y el fascismo español, Madrid, Síntesis, 2005.

15 R. Ledesma Ramos, Escritos politicos 1931, Madrid, s. e. 1986, p. 46. 
Aunque no se mencionaba la palabra fascismo, la aparición del grupo de La Conquista del Estado representaba la irrupción de la primera opción política inequívocamente fascista en España. Surgido en un momento de fuerte tensión política, con la Derecha en plena reorganización y a escasas semanas del inicio de una serie de consultas electorales en las que la Monarquía se jugaba el futuro, su nacimiento pasó un tanto desapercibido. Sufría el grupo, además, un problema común a todas las organizaciones del fascismo español anterior a la guerra civil: la escasez extrema de medios económicos. Aun así, a través del financiero José Félix de Lequerica y del diplomático José Antonio de Sangróniz, consiguieron algunos fondos que les permitieron mantener la edición del periódico hasta octubre de 1931.

En paralelo con el grupo madrileño habían aparecido en Valladolid unas Juntas Castellanas de Actuación Hispánica. Su líder, Onésimo Redondo, licenciado en Derecho, había sido lector de español en la universidad alemana de Mannheim, entre 1927 y 1928, donde parece haberse familiarizado con la doctrina nazi ${ }^{16}$. Militante católico e impulsor de un sindicato de pequeños labradores, fundó las Juntas con una visión doctrinal que «apenas tenía algo que ver con el radicalismo fascista de Ledesma ${ }^{17}$. Predominaban el nacionalismo imperialista y tradicionalismo católico, la apelación a la juventud a construir un Estado totalitario mediante una «revolución hispánica», y una retórica antisemita y antiliberal parejas a un antimarxismo visceral ${ }^{18}$. Las JCAH, que contaron desde junio de 1931 con su propio semanario, Libertad, no superaron el ámbito provincial, donde poseían una modesta base de militancia en la que predominaban estudiantes y pequeños agricultores.

Los dos grupúsculos fascistas estaban obligados a entenderse, si querían superar sus precarias condiciones. En octubre de 1931 se fusionaron en las Juntas de Ofensiva Nacional Sindicalista (JONS). Durante los meses siguientes, con Ledesma como principal ideólogo, los jonsistas refinaron su programa, hasta darle una estructura doctrinal que denominaron nacionalsindicalismo, en la que el radicalismo social ledesmista, con fuertes ecos sorelianos, se aunaba con el más marcado componente nacionalista y católico del grupo vallisoletano. Las Juntas atrajeron alguna financiación, procedente de medios empresariales, y extendieron su ámbito a diversas ciudades con universidad, donde se formaron pequeños grupos de activistas. Pero sus primeras acciones de $\left\langle\right.$ violencia saludable» ${ }^{19}$, sobre todo contra los estudiantes izquierdistas de la FUE, y el fracasado golpe de Estado derechista de agosto de 1932 frustraron su desarrollo por la reacción de los responsables del orden público. A consecuencia de la sanjurjada Ledesma, que no había participado en la trama, fue encarcelado y Redondo, que sí estaba implicado, huyó a Portugal, mientras que las JONS fueron ilegalizadas, aunque siguieron manteniendo actividad clandestina. Por su parte, el Partido Nacionalista Español, semillero de jóvenes fascistizantes, tuvo una actuación demasiado evidente en apoyo del golpe y también fue ilegalizado. Aún sin pretenderlo, el fascismo hispano tenía ya su putsch de Múnich.

16 J. L. Mínguez Goyanes, Onésimo Redondo, 1905-1936. Precursor sindicalista, Madrid, Editorial San Martín, 1990; J. L. JeREz RiesCO, «El abanderado nacionalsindicalista de Castilla: biografía breve de Onésimo Redondo, en Aportes, $\mathrm{n}^{\circ}$ 58, 2005, p. 172-198.

17 P. C. González Cuevas, "La trayectoria de un recién llegado. El fracaso del fascismo español», en F. Del Rey (dir.), Palabras como puños. La intransigencia politica en la Segunda República Española, Madrid, Tecnos, 2011, p. 494.

18 Sus escritos doctrinales de 1931 en O. Redondo, Textos políticos, Madrid, Doncel, 1975, p. 9-121.

19 «La revolución social», texto sin firma de O. REDONDO en Libertad, n², 20-6-1931. 


\section{El año crucial de 1933}

A comienzos de ese año, las perspectivas de crecimiento del fascismo en España eran aún más débiles que las de los primeros meses de 1931. Entonces no existían partidos consolidados en la Derecha, tras la tabula rasa primorriverista, y el fascismo aparecía como una solución políticamente virgen en el país frente al inminente peligro de una revolución social, aureolado además de vanguardismo intelectual. Pero tres años después, el sector político que se reclamaba cercano al modelo mussoliniano había quedado reducido a su mínima expresión, fracasados sus grupos tras un desarrollo canijo, y la República parlamentaria parecía consolidada merced a un pacto republicano-socialista que aún parecía sólido.

Si a lo largo de 1933 resurgió el proyecto de consolidar un partido fascista en España, se debió, en gran medida, a dos procesos externos:

- En enero de 1933, Adolf Hitler llegó a la presidencia del Gobierno alemán tras unas elecciones y en los meses siguientes su Partido Nacionalsocialista inició los pasos para transformar a la República de Weimar en un Estado totalitario. En principio, el proceso se realizaba en coalición con las fuerzas conservadoras alemanas y la derecha radical española se entusiasmó con la forma en que se estaba barriendo a la izquierda germana. Desde la altura intelectual de un Ramiro de Maeztu hasta el prosaísmo de un Albiñana, los colaboradores de las publicaciones monárquicas llevaban meses deshaciéndose de elogios hacia «el camarada Hitler», como le llamaba el líder del PNE ${ }^{20}$. Y para los fascistas, fascistizantes y fascistizados del país, el éxito del NSDAP era una irrenunciable incitación a la acción.

- Por otro lado, la trabajosa reorganización de la Derecha nacional culminó, en febrero de 1933, con la creación por los monárquicos partidarios de Alfonso XIII de un partido conservador autoritario, Renovación Española ${ }^{21}$. El desarrollo de RE se vio enseguida seriamente limitado por la rivalidad con los dos grandes bloques derechistas: la naciente Confederación Española de Derechas Autónomas (CEDA), que aglutinaba al confesionalismo católico, y la Comunión Tradicionalista, que reunificó al carlismo. Con una reducida afiliación integrada por aristócratas y burgueses, RE carecía de la masa popular que apoyaba a sus dos rivales. Pero disponía, en cambio, de abundantes recursos económicos, de influyentes medios de comunicación, de amplias simpatías en la oficialidad del Ejército y de una militancia decidida a terminar con la República por cualquier medio. No es extraño que, en el año de Hitler, se les apareciera como solución lo que atrajo a muchos conservadores alemanes e italianos: la utilización de un fascismo «domesticado» como catalizador de las masas hacia el objetivo de acabar con el régimen parlamentario liberal y proscribir la actuación de la izquierda obrera.

A lo largo de 1933 se dieron tres intentos de relanzar el fascismo en España. La base de partida organizativa era prácticamente inexistente, por lo que estaba casi todo por hacer en lo tocante a la puesta en marcha de un partido que tendría que aspirar a ser una organización de masas. Pero se podían sacar lecciones de los fracasos anteriores y existía

20 R. de Maetzu, «El milagro Hitler», $A B C, 20-4-1932$; J. M. Albiñana, «Cosechando triunfos. E1 camarada Hitler», La Nación, 4-5-1932 y «Hacia la nueva España. El fascismo triunfante», Renacer, 12-3-1933. Una visión global en M. SEmolinos, Hitler y la prensa de la II República española, Madrid, CIS, 1985.

21 J. Grl Pecharroman, Conservadores subversivos. La derecha autoritaria alfonsina, 1914-1936, Madrid, Eudema, 1994. 
un aceptable nivel de asimilación de las doctrinas fascistas entre algunos elementos de la derecha radical, además de los jonsistas, de fascismo ya acreditado. Y estaba la voluntad de patrocinio de los monárquicos alfonsinos y, entre ellos, de Manuel Delgado Barreto, el «periodista garduño», como le definió Ledesma, dispuesto a recuperar su papel de muñidor de operaciones políticas.

Quienes primero se descolgaron con una reivindicación de partido fascista fueron los albiñanistas. Durante la primera mitad de 1933, el PNE pudo reorganizarse, aún en la clandestinidad, y su Juventud Nacionalista, con el apoyo de La Nación, el periódico de Delgado, y de alguna otra publicación filo-fascista vinculada a Renovación Española -Renacer, Aspiraciones - se embarcó en una campaña de exaltación de las virtudes del fascismo. Existen testimonios gráficos mostrando a los legionarios de España portando brazaletes con la cruz gamada sobre sus camisas azules en actos públicos durante la primavera. Pero Albiñana no era, desde luego, un líder fascista y, tras retornar de un largo confinamiento gubernativo, acabó desautorizando al sector fascistizado del partido, cuyos jóvenes terminaron integrándose en las JONS y en Falange. El PNE volvió entonces a la senda de la derecha radical monárquica y acabaría su peripecia integrándose, en 1937, en la Comunión Tradicionalista.

Ledesma y Redondo asumieron el relanzamiento de las JONS y lograron que sus protectores, banqueros vizcaínos, reanudaran la siempre parca financiación, con los alfonsinos Lequerica y José María de Areilza como intermediarios. Pero, una vez más, el empeño resultó frustrante. Sacaron una publicación doctrinal, la revista JONS, donde Ledesma y sus colaboradores siguieron fijando las bases del nacionalsindicalismo ${ }^{22}$. Pero era cada vez más evidente que su defensa una «revolución» fascista, anticapitalista y republicana, disgustaba a monárquicos y cedistas y alejaba cualquier apoyo substancial que los medios conservadores pudieran aportar al jonsismo. Este volvió, por otra parte, a ejercer la violencia política a través del escuadrismo, pero sus actuaciones, como el violento saqueo de la sede madrileña de la Asociación de Amigos de la Unión Soviética, en el mes de julio, le atrajeron la hostilidad de las organizaciones obreras y la represión gubernativa. Cuando se convocaron elecciones parlamentarias, en el otoño, los jonsistas estudiaron presentar alguna candidatura, pero acabaron desistiendo ante lo escaso de su fuerza. En su segunda etapa, «las JONS fueron un rotundo fracaso» ${ }^{23}$.

En este panorama, Delgado Barreto buscó repetir la operación de La Camisa Negra con una iniciativa periodística que sentara las bases teóricas y lanzara a los dirigentes necesarios para la creación de una organización fascista de masas. Con apoyo de la embajada italiana, con la que mantenía estrecha relación, preparó el lanzamiento de El Fascio. Haz Hispano, una revista en cuyo informal comité de redacción se integraron los jonsistas Ledesma, Giménez Caballero y Juan Aparicio, el escritor Rafael Sánchez Mazas, el aviador Julio Ruíz de Alda y el abogado José Antonio Primo de Rivera, marqués de Estella, primogénito del fallecido dictador, que había sido vicesecretario general de la Unión Monárquica Nacional y era uno de los principales accionistas de La Nación. Moderadamente liberal en su primera juventud-ahora tenía treinta años-desde 1932 experimentaba una aproximación intelectual al fascismo ${ }^{24}$.

22 El contenido de la revista está publicado en JONS, órgano teórico de las Juntas de Ofensiva Nacional Sindicalistas, Madrid, Ediciones Barbarroja, 2011.

23 J. M. Thomás, Los fascismos españoles..., p. 77.

24 Entre sus biografías más recientes se encuentran J. Gll Pecharromán, José Antonio Primo de Rivera. Retrato de un visionario, Madrid, Temas de Hoy, 1996; S. G. PAYne., Franco y José Antonio. El extraño 
El Fascio apareció el 16 de marzo de 1933, no por casualidad tercer aniversario de la muerte del dictador. Contenía un popurrí de colaboraciones, desde un artículo de Ledesma sobre el sentido de las JONS y otro de Aparicio llamando a la movilización de la juventud española - «la trinchera fascista nos espera ansiosa», escribía- hasta dos breves elucubraciones teóricas de Primo de Rivera, tituladas «Hacia un nuevo Estado» y «El fascio no es un régimen esporádico». Pero la revista, recogida por la policía en los quioseos, no tuvo continuidad ante la enérgica reacción del Gobierno y de las organizaciones de izquierda ${ }^{25}$.

El frustrado intento tuvo, no obstante, la consecuencia de lanzar la figura del joven Primo de Rivera hacia la reducida constelación de líderes fascistas españoles, favorecido por la subsiguiente polémica sobre el sentido y las posibilidades de un fascismo español que mantuvo en las páginas de $A B C$ con el liberal-conservador Juan Ignacio Luca de Tena. En los meses centrales de 1933, José Antonio -como le conocerían sus seguidoresfue aglutinando un núcleo político integrado por amistades personales, nostálgicos primorriveristas, incluido un grupo de militares retirados, y estudiantes ganados para las ideas fascistas. Con ellos, y con Ruíz de Alda como colíder creó, en julio de 1933, el Movimiento Español Sindicalista-Fascismo Español. Enseguida se les unió el minúsculo Frente Español, formado por nacionalistas de raíz orteguiana y dirigido por Alfonso García Valdecasas, quien pasó a formar parte del triunvirato director del MES, con Primo de Rivera y Ruíz de Alda.

El pequeño partido se acercaba, mucho más que las JONS, al modelo de fascismo «domesticado» que buscaban los monárquicos y en agosto Primo de Rivera acordó con Antonio Goicoechea, presidente de Renovación Española, el conocido como Pacto de El Escorial, por el que, a cambio de una modesta financiación, el MES se comprometía a no atacar a la Monarquía y admitía notables afinidades doctrinales con el grupo alfonsino. La preseneia de militares veteranos -Rodríguez Tarduchy, Alvargonzález, Rada, el propio Ruíz de Alda- en el encuadramiento de la futura Milicia del partido parecía garantizar un cierto control conservador de sus acciones. Y aquellos de los primeros afiliados que poseían un basamento doctrinal -caso de Sánchez Mazas- estaban más cerca de la «derecha» fascista italiana que del radicalismo de sinistra del grupo de Ledesma. El propio Primo de Rivera, converso reciente a las doctrinas mussolinianas, era un católico muy tradicional, fuertemente influenciado por el pensamiento tomista y los tradicionalistas españoles del XIX, pero también por Ortega y Spengler, y que mantenía estrechas relaciones con la cúpula alfonsina y con los intelectuales neotradicionalistas -Maeztu, Vegas Latapié- de la revista Acción Española ${ }^{26}$.

Los monárquicos patrocinaron, con el asentimiento de los cedistas, la candidatura a Cortes de José Antonio por Cádiz, que a finales de 1933 le convirtió en diputado. Para entonces había tenido lugar el «acto de afirmación españolista» del Teatro de la Comedia, en Madrid (29 de octubre) en el que el triunvirato dirigente del MES presentó un proyecto político, aunque sin concretar sus bases programáticas, de fascismo nacional, católico, antiliberal, antimarxista y defensor de la «dialéctica de los puños y las pistolas» como

caso del fascismo español, Barcelona, Planeta, 1997 y A. Imatz, José Antonio, entre el amor y el odio. Su historia como fue, Madrid, Altera, 2006.

25 El número completo se puede consultar en http://www.filosofia.org/hem/193/fas/index.htm

26 M. Argaya Roca, Entre lo espontáneo y lo dificil. (Apuntes para una revisión de lo ético en el pensamiento de José Antonio Primo de Rivera), Oviedo, Tarfe, 1996. Un estudio de sus primeros escritos políticos en M. Simancas, José Antonio. Génesis de su pensamiento, Madrid, Plataforma 2003. 
método legítimo de acción política. Cuatro días después, el MES cambió su nombre por el de Falange Española (FE).

\section{FE de las JONS}

Falange arrancó con unos pocos centenares de afiliados, especialmente en Madrid y Andalucía occidental, mientras que en diversas capitales de provincias surgían pequeños núcleos, en no pocas ocasiones por iniciativa personal de quien se convertía en jefe provincial. Desde el principio, la Falange y su rama estudiantil, el Sindicato Español Universitario (SEU) -que, pese a su nombre, permitía encuadrar a adolescentes sin edad legal para afiliarse a $\mathrm{FE}$ - se vieron implicados en una espiral de violencia callejera frente a los sectores más radicalizados del movimiento obrero, que dejó un creciente número de muertos y heridos. La Milicia juvenil de FE, la «primera línea», organizada por exmilitares monárquicos y con uno de ellos, el exaltado aviador Juan Antonio Ansaldo como «jefe de objetivos», parecía, en principio destinada a ser el elemento de atracción y encuadramiento que facilitara el crecimiento del partido. Pero éste era tan pequeño que la Milicia distaba de ser efectiva. Entre diciembre de 1933 y febrero del año siguiente, murieron cinco falangistas en enfrentamientos callejeros sin que, por prudencia o por incapacidad, la naciente «primera línea» de FE replicara con un nivel de violencia similar. Ello disgustaba a los monárquicos, que esperaban un rápido incremento de la violencia desestabilizadora y que constataban que «un fascismo así no es más que literatura, sin riesgo alguno para los adversarios $)^{27}$.

Uno de los problemas que se le planteaban a $\mathrm{FE}$ a corto plazo era la competencia por el marchamo de «fascista» que le hacían las JONS. Existía una cierta hostilidad entre ambos grupos, que los monárquicos parecían dispuestos a estimular con criterio darwiniano. Pero Falange tenía casi todas las ventajas: mayor afiliación, una financiación más abundante y dos diputados en Cortes, Primo de Rivera y el marqués de la Eliseda, cuya inmunidad parlamentaria les garantizaba una libertad de acción que no poseían los líderes jonsistas. Pero las estrecheces económicas y la debilidad de la afiliación y de la estructura territorial de los dos grupos aconsejaban el pacto. Tras varios contactos renuentes, ambos llegaron a un acuerdo de fusión en un único partido, Falange Española de las JONS ${ }^{28}$.

En teoría, la unificación de los dos sectores fascistas se producía en igualdad de condiciones. Pero pronto fue evidente que los primorriveristas le habian sacado mayor partido. En adelante, el fascismo español sería «falangismo», obviando la aportación jonsista. El triunvirato director lo formaron dos falangistas, Primo de Rivera y Ruíz de Alda, y un jonsista, Ledesma, aunque inmediatamente fue José Antonio, aristócrata y diputado, quien acaparó la atención política y mediática y comenzó a dejar entrever su intención de reclamar para sí el caudillaje único del partido. No obstante, las JONS aportaron importantes elementos a la fusión: una incipiente estructura sindical, que se

27 Álvaro Alcalá Galiano en $A B C, 13-2-1934$.

28 Entre los estudios sobre FE-JONS pueden señalarse los clásicos de S. G. PAYNE, Falange. Historia del Fascismo Español, París, Ruedo Ibérico, 1965 y J. JimÉnez CAMPO, El fascismo en la crisis de la II República, Madrid, CIS, 1979, y obras más recientes, como J. M. THомÁs, Lo que fue la Falange, Barcelona, Plaza \& Janés, 1999; J. L. Rodriguez Giménez, Historia de Falange Española de las JONS, Madrid, Alianza Editorial, 2000; M. Penella, La Falange teórica, Barcelona, Planeta, 2006; y M. Peñalba, Falange española: historia de un fracaso (1933-1945), Pamplona, Eunsa, 2009. 
formalizó en el verano de 1934 en la Central Obrera Nacional Sindicalista (CONS) ${ }^{29}$; un concepto triunviral en el conjunto del organigrama del partido; símbolos, como la bandera rojinegra o el emblema del yugo y las flechas; y, sobre todo, una variante hispánica de las doctrinas del fascismo, el nacionalsindicalismo, elaborada por Ledesma, Redondo y otros teóricos jonsistas a lo largo de tres años y de la que, sin embargo, Primo de Rivera acabaría siendo el referente fundamental en un futuro muy próximo.

Un movimiento anti-sistema como era el fascismo en la España de los primeros años treinta, necesitaba de unas condiciones duras de confrontación política y social para crecer y recabar apoyos exteriores. En el momento en que apareció el MES en el escenario politico, existían las condiciones favorables para su desarrollo: coalición de gobierno del centro-izquierda con participación socialista, políticas estatales reformistas rechazadas por los sectores conservadores, laicismo oficial con orientación anticlerical, implantación de un sistema autonómico al que la Derecha veía como una seria amenaza para la unidad nacional, desarrollo de una recesión económica que generaba un amplio paro en el sector industrial, etc. Pero tras la aparición de Falange, gran parte de esas condiciones variaron en favor de los intereses de las derechas, comenzando por el cambio de mayorías parlamentarias en noviembre de 1933 .

La formación de gobiemos de centro-derecha republicano con apoyo cedista y, luego, la entrada de la propia CEDA en el Ejecutivo, crearon en la mayoría del espectro conservador y en el aparato eclesial fuertes expectativas posibilistas sobre una modificación legislativa del proyecto republicano. A partir de los sucesos de octubre de 1934 -fracaso del movimiento revolucionario socialista y de la sedición de las instituciones autonómicas catalanas, gobernadas por la izquierda nacionalista- la situación conservadora pareció consolidada mediante un proceso que podía incluso conducir a una dictadura confesional y corporativa en manos de la CEDA o, al menos, a un sistema semi-autoritario de «democracia vigilada» similar a los que se deban en la Polonia de los coroneles o en la Hungría del regente Horty. Y esas no eran, evidentemente, las condiciones adecuadas para el crecimiento de un fascismo que, en el bienio «rectificador» fue contemplado por las autoridades como un molesto problema de orden público que había que controlar, pues si su mera existencia era una amenaza para la izquierda, no estaban dispuestas a permitir que supusiera un peligro para el orden constitucional o para el sistema socio-económico vigente.

El naciente fascismo español sólo podía acudir, por lo tanto, a la ayuda extranjera, o a la colaboración con otras fuerzas anti-sistema, que no podían ser sino los monárquicos. Tras el fiasco de El Fascio, el fascismo italiano se mostró siempre crítico con las posibilidades de desarrollo de sus correligionarios hispanos, y sus aportaciones económicas fueron relativamente escasas incluso cuando, a partir de abril de 1935, Roma se convirtió en la principal fuente de subvenciones externas para la Falange, una vez que los alfonsinos le hubieron retirado su ayuda ${ }^{30}$.

Las relaciones de las JONS y de Falange con estos, antes y después de la unificación de ambas formaciones, constituyen todavía hoy uno de los aspectos más oscuros de la historia del fascismo español. Hasta el otoño de 1934, los dirigentes de RE ejercieron un evidente tutelaje, apoyado en su aportación financiera al sostenimiento de FE y en la ayuda logística que suponían diversos elementos «prestados», como los militares que encuadraban a la milicia

29 J. A. Llopart (ed.), Central Obrera Nacional Sindicalista. Textos de y sobre los primeros sindicatos falangistas (1934-1937), Barcelona, Ediciones Nueva República, 2012.

30 I. Saz Campos, Mussolini contra la II República, Valencia, Edicions Alfons el Magnànim, 1986, p. 138-146. 
o los medios de comunicación amigos, ante las dificultades del falangismo para sostener sus escasas y efímeras publicaciones. El punto cenital de esta dependencia estaría marcado por el pacto alcanzado entre José Antonio y el presidente de RE, Goicoechea, en agosto de 1934, por el que a cambio de una financiación regular de los alfonsinos los falangistas se comprometían a lograr «el máximo incremento de las milicias de combate» de FE, embarcadas en una espiral de violencia, $\mathrm{y}$ a potenciar su «organización obrera antimarxista».

A la altura de ese verano, Falange había dado ya los pasos necesarios para entrar en una confrontación abierta con las organizaciones de la izquierda obrera. Era, fundamentalmente, una lucha de jóvenes radicalizados en la que no cabían las finuras doctrinales a la hora de combatir al enemigo o crear crispación en la ciudadanía. Y era una lucha con una progresión en el grado de la violencia. A los iniciales choques callejeros entre voceadores de prensa, o a las peleas en universidades e institutos, siguió una violencia más institucionalizada, que se alimentaba con la mística de los «caídos» del movimiento. Ansaldo organizó una sección de pistoleros -hoy los definiríamos como terroristas- que se conoció como «la Falange de la sangre» y que se especializó, apoyándose en la justificación doctrinal de los teóricos del partido, en provocaciones y represalias, comenzadas con el asesinato a sangre fría de la joven socialista Juana Rico, en una calle de Madrid ${ }^{31}$.

Para el sector del falangismo que se sentía más próximo a los principios «revolucionarios» del fascismo, la dependencia de los monárquicos era un elemento sumamente negativo, por cuanto situaba a FE en el campo de la ultraderecha reaccionaria. Y esto sucedía también con Primo de Rivera, cuya aspiración a convertirse en líder único del fascismo español se veía seriamente limitada por su imagen de aristócrata políticamente criado a los pechos de los monárquicos. La fusión con el jonsismo, y probablemente un viaje que realizó a Alemania en mayo de 1934, facilitaron a José Antonio una profundización en su proceso de fastistización que le llevó a mostrarse cada vez más renuente con el control político que demandaban sus financiadores monárquicos. En las Cortes renunció a actuar en la minoría de Renovación Español y, como diputado independiente, tuvo intervenciones que sonaban manifiestamente antimonárquicas. Cuando, en la primavera de 1934, retornó del exilio José Calvo Sotelo y quiso afiliarse a Falange con el consentimiento de Ledesma y Ruíz de Alda, José Antonio entendió, probablemente con razón, que el exministro pretendía disputarle su puesto en la jefatura y vetó su ingreso, tachándole de reaccionario. Y luego, en octubre, protagonizó el rechazo falangista a unirse al Bloque Nacional, la plataforma de fuerzas contrarrevolucionarias que estaba poniendo en marcha Calvo Sotelo con el apoyo de las minorías parlamentarias monárquicas.

Estas actitudes de creciente autonomía tendrían un precio. Durante el verano de 1934, Ansaldo intentó un mal conocido golpe de mano para desplazar a José Antonio de la dirección falangista. Fracasó, pero los monárquicos no tardaron mucho en retirar a sus asesores militares, lo que dificultó el encuadramiento de la Milicia falangista. Y cuando, en octubre, se publicaron los 27 puntos programáticos, debidos fundamentalmente a la pluma de Primo de Rivera, el otro diputado falangista, el acaudalado marqués de la Eliseda, acusó a madrileño de «hereje» por defender la separación del Estado y de la Iglesia y retiró su fundamental aportación económica a FE, al igual que hicieron los responsables de Renovación Española. Incluso el diario La Nación, hasta entonces el principal

31 E. González Calleja, «Puños y pistolas. Doctrinas y justificaciones de la violencia en el fascismo español durante la Segunda Repúblican, Bulletin d'Histoire Contemporaine de l'Espagne, $\mathrm{n}^{\circ} 44$, Aixen-Provence, PUP, 2010, p. 233-262. 
medio de difusión del falangismo, cerró prácticamente sus páginas a la propaganda nacionalsindicalista. Era, en gran medida, un intento de presionar a Falange para que se integrara en el Bloque Nacional, por lo que su reiterada negativa hundió al partido en una grave crisis económica, que prácticamente paralizó su funcionamiento.

\section{Una singladura en solitario}

A comienzos de octubre de 1934, por otra parte, la trayectoria interna de FE sufrió un brusco giro, que marcó su historia posterior. El día 5, momento de inicio de los sucesos revolucionarios de Asturias, se reunió en Madrid el primer Consejo Nacional de la Falange. Se debatieron asuntos doctrinales en torno a las esencias del nacionalsindicalismo, se adoptó la camisa de color azul mahón como uniforme del partido y, sobre todo, se planteó la cuestión de la jefatura, que desde antes de la fusión enfrentaba a los joseantonianos de FE y a los ledesmistas de las JONS. Los primeros defendían, en coherencia con la naturaleza del fascismo, una jefatura unipersonal indiscutible, un caudillo del movimiento que, dadas las circunstancias, no podía ser otro que el diputado Primo de Rivera. Los jonsistas se negaban a ello y querían mantener la estructura triunviral como un eficaz método de autocontrol en todos los niveles organizativos. El asunto se resolvió mediante una votación democrática que, por un solo voto, entregó el mando como jefe nacional a José Antonio. Este se apresuró a colocar a sus partidarios en la Junta Política del partido y asumió la redacción de los 27 puntos del sintético programa de FE-JONS, marginando aún más a Ledesma. Este, consciente de su derrota, intentó una sonora escisión de sus seguidores para refundar las JONS. Pero Primo de Rivera, alertado por Delgado Barreto, se adelantó a expulsar a Ledesma y unas docenas de los suyos el 16 de enero de 1935 y consiguió que los sindicalistas de la CONS, así como Redondo y el importante núcleo vallisoletano, permanecieran casi en bloque en las filas de Falange.

A lo largo de 1935, FE mantuvo una vida mortecina, condenada a una permanente penuria económica y con un Gobierno controlado por la CEDA al que no agradaba nada el despliegue de la violencia fascista. Durante meses, José Antonio y su amigo y mano derecha, el secretario general Raimundo Fernández-Cuesta, se aplicaron, sin rehuir las depuraciones, en el control de las organizaciones provinciales de la Falange y de los dos antiguos reductos del ledesmismo, el SEU estudiantil y, sobre todo, la CONS cuyo líder, Manuel Mateo, era un antiguo comunista ${ }^{32}$. A finales de año, la jefatura carismática de Primo de Rivera estaba asegurada y el partido, con una afiliación modesta pero que seguía creciendo hasta alcanzar, probablemente, unos diez mil afiliados, era un mecanismo bien engranado, con la Milicia y el aparato de propaganda desarrollados conforme a los cánones ortodoxos del fascismo. La financiación italiana acabó garantizando una mínima estabilidad y Falange pudo dotar de continuidad a su órgano periodístico, el semanario Arriba, aparecido en marzo de 1935.

A lo largo de ese año, José Antonio Primo de Rivera se esforzó por ampliar el eco de su partido, y de su propia persona, en la vida política. Como diputado combatió, por pusilánime, la labor parlamentaria y gubernamental de la coalición radical-cedista durante lo que llamó el «bienio estéril» y en no pocas ocasiones actuó como un auténtico opositor. Mantenía, como todos los falangistas, una abierta hostilidad contra la izquierda marxista y contra los nacionalismos periféricos, sectores políticos que identificaba con la anti-España. Pero no

32 J. Onrubia Revuelta, Manuel Mateo y la CONS, Oviedo, Nuevo Cauce, 1985. 
dudaba en lanzar sus dardos contra la monarquía de Alfonso XIII, a quien no perdonaba la forma que había despojado del poder a su padre, el dictador. Derechas e izquierdas tenían, pues, motivos, aunque muy distintos, para combatir el auge de un fascismo que preconizaba un modelo de Estado totalitario a través de la Revolución nacionalsindicalista.

Experimentó José Antonio, por otra parte, un proceso de radicalización ideológica que, en esos meses, fue compartido por la militancia falangista ${ }^{33}$. En sus inicios políticos -tan sólo dos años atrás-el líder de FE, preocupado tanto o más por el «estilo» que por la acción, había gustado de rodearse de intelectuales, políticamente diletantes ${ }^{34}$, y había sido identificado con planteamientos monárquicos y católicos, socialmente conservadores, que chocaban con la «modernidad» totalitaria de un Ledesma Ramos. Pero tras la marcha de este y tras la ruptura política con los alfonsinos, convertido en ideólogo del nacionalsindicalismo, José Antonio asumió posiciones crecientemente radicalizadas, que expuso en una serie de actos públicos y en numerosos artículos: Estado «fuerte» de partido único, con economía dirigida y en gran parte estatalizada, reforma agraria, control de las plusvalías empresariales por las corporaciones laborales estatales, que integrarían en pie de igualdad a patronos y obreros, rechazo a la intromisión clerical en las políticas estatales, etc. Por otro lado, fortaleció en su discurso una negativa cada vez más firme a identificar falangismo con fascismo, afirmando las peculiaridades específicas del nacionalsindicalismo con respecto a los modelos italiano o alemán. Sin embargo, la opinión pública no llegaba a captar tales sutilezas y en los medios de comunicación se siguió identificando a los falangistas como fascistas.

$\mathrm{Si}$ algo preocupaba a los estrategas del partido casi tanto como el triunfo de una revolución de tipo bolchevique era una dictadura confesional y ultraconservadora, como la que en los meses centrales de 1935 parecía dispuesto a impulsar el líder de la CEDA y ministro de la Guerra, Gil-Robles. En tal caso, las posibilidades de crecimiento de FE, incluso su misma existencia, se verían seriamente comprometidas en el marco de un régimen de conservadurismo autoritario. Pero este ni siquiera podría implantarse si se cumplían las predicciones de José Antonio sobre la inminencia de una revolución marxista en España.

En estos meses, pues, la dirección falangista se preocupó de acelerar la preparación paramilitar de la Milicia del partido, y planificó una suerte de «marcha sobre Roma» que llevaría a sus milicianos, con la ayuda de los numerosos oficiales del Ejército que simpatizaban con sus ideas, a hacerse con el control de Madrid a fin de acabar con la amenaza izquierdista e instalar rápidamente el Nuevo Estado nacionalsindicalista. José Antonio difundió escritos en los cuarteles animando a la colaboración de los militares, se entrevisto a tal efecto con el general Francisco Franco, que no le hizo caso alguno, e incluso, en diciembre, quiso poner en marcha el plan golpista sublevando a la guarnición militar de Toledo para que marchara sobre la capital en compañía de la Milicia falangista. Pero la pequeña FE no tenía capacidad para acabar con el sistema constitucional republicano y los generales, sin cuya participación eso era imposible, no estaban dispuestos a subordinarse a los planificadores civiles del futuro Estado nacionalsindicalista.

33 Existe una amplia, e irregular bibliografía de exégesis del pensamiento joseantoniano. La mejor referencia son las obras completas de José Antonio, aunque no las sucesivas ediciones de «obras escogidas», cuya selección respondía a criterios muy discutibles. La edición canónica de las Obras Completas es la recopilada en dos tomos por A. Del Río Cisneros para la Editora Nacional, en 1976 (hay una edición virtual en rumbos.net). Existe, sin embargo, una edición con nuevas aportaciones, recopiladas por R. IBÁNEZ para Plataforma 2003.

34 Sobre este entorno, P. y M. CARbajosa, La corte literaria de José Antonio. La primera generación cultural de la Falange, Barcelona, Crítica, 2003. 
Cuando se convocaron las elecciones de febrero de 1936, FE-JONS estaba, pues, en un riguroso aislamiento político, destinado a preservar su autonomía, con muy escasos medios materiales y sin un proyecto realista que le permitiera convertirse en una fuerza hegemónica de la Derecha a corto plazo. Los comicios supusieron un fuerte varapalo moral: la dirección falangista se negó a subordinarse a la coalición derechista que estaba aglutinando Gil-Robles si no se le garantizaba un crecido número de actas parlamentarias seguras. Ante la negativa de los conservadores, los falangistas concurrieron en solitario en una docena de provincias, con una campaña muy escasa de medios, en la que mostraron su alejamiento de las derechas y de las izquierdas - «contra unos y contra otros» fue uno de sus eslóganes electorales- y pudieron exponer abiertamente al electorado su proyecto de Estado totalitario. Cosecharon el 0,4 por ciento de los votos emitidos y no lograron ningún acta. Ello iba a ser dramático a corto plazo: sin inmunidad parlamentaria, Primo de Rivera quedaba a merced de los tribunales ordinarios para responder por sus actuaciones y las de su partido.

Las elecciones de febrero de 1936 trajeron un cambio radical en las condiciones de la política nacional, que alteró el rumbo, hasta entonces tan poco brillante, del falangismo. La obtención de la mayoría parlamentaria absoluta por el Frente Popular de izquierdas y la formación de un Gobierno de izquierda republicana fueron contempladas por el conjunto de la opinión derechista como la antesala de una revolución de tipo bolchevique. Súbitamente, cualquier interés que pudiera haber tenido el parlamentarismo para las «gentes de orden» desapareció ante la percepción de que era urgente desarrollar a corto plazo una contrarrevolución que pusiera fin a la democracia republicana. Y Falange, una organización que repudiaba el sistema parlamentario y el pluralismo político y que defendía la acción paramilitar violenta como forma de lucha contra el movimiento obrero, se benefició enseguida de una afluencia a sus filas de miles derechistas crecientemente radicalizados -jóvenes cedistas y alfonsinos muchos de ellos- que buscaban en la «primera línea» de FE-JONS una rápida y expeditiva vía de acción contra el frentepopulismo.

A lo largo dela primavera de 1936, Falange se implicó, pues, en prácticas desestabilizadoras de terrorismo callejero, como el intento de asesinato del diputado socialista Jiménez de Asúa, que encontraron respuesta en las juventudes de las organizaciones obreras y que produjeron una elevada cifra de muertos. Una espiral de represalias sangrientas era algo que el Gobierno no estaba dispuesto a tolerar, sobre todo porque el miedo a un golpe fascista comenzaba a ser una realidad apremiante entre las bases sociales del Frente Popular. El 14 de marzo, José Antonio y gran parte de la dirección falangista fueron detenidos e ingresados en la Cárcel Modelo, de Madrid, mientras que las actividades del partido y aún la militancia en él, fueron prohibidas. Pero Falange reconstruyó rápidamente su estructura en la clandestinidad y sus comandos siguieron tomando parte muy activa en la difusión de la desestabilizadora violencia política.

Cuando, a finales de la primavera, se puso en marcha la conspiración militar organizada por la Junta de Generales, y estos buscaron la colaboración de los partidos derechistas, con la exigencia de que se subordinaran al mando militar, antes y durante el golpe de Estado, la actitud de FE-JONS se convirtió en un elemento clave. Se comprobó entonces el aspecto negativo de la decisión tomada en octubre de 1934, que otorgó a José Antonio, como jefe nacional, el control prácticamente absoluto de la organización. Desde la cárcel -sobre todo cuando, el 5 de junio, fue trasladado a la de Alicante- resultaba imposible controlar una organización que se desenvolvía en la clandestinidad. Y nadie podía asumir el liderazgo 
carismático del madrileño. En consecuencia, algunos jefes provinciales comenzaron a actuar con autonomía y ello se tradujo en negociaciones contradictorias con los militares.

Para Primo de Rivera había sonado la hora de lanzarse a la destrucción de la República. A comienzos de junio publicó en el boletín clandestino del partido, No Importa, un llamamiento a la lucha armada: «iBien haya esta violencia, esta guerra, en la que no sólo defendemos la existencia de la Falange [... s sino la existencia misma de España, asaltada por sus enemigos! Seguid luchando camaradas, solos o acompañados. Apretad vuestras filas, aguzad vuestros métodos. Mañana, cuando amanezean más claros días, tocarán a la Falange los laureles frescos de la primacía en esta santa cruzada de violencias $\rangle^{35}$.

Pero, de momento, lo que tocaba era subordinarse a los generales para hacer triunfar el golpe militar. José Antonio, que consideraba a los conspiradores como un grupo de reaccionarios nada proclives al falangismo, mostró sus reticencias a la colaboración durante varias semanas. E1 24 de junio, en una circular, ordenó a los afiliados que se negaran a poner su organización bajo el mando militar, ya que ello llevaría a FE a «la total desaparición, aún en el caso de triunfo ${ }^{36}$. Pero cinco días después, presionado por algunos amigos y correligionarios, cedió y autorizó a los mandos provinciales a pactar con los militares los términos de su intervención en el alzamiento, siempre que Falange pudiese mantener su autonomía como partido y como organización de milicias.

Cuando, el 17 de julio, las guarniciones peninsulares y del Protectorado de Marruecos comenzaron a pronunciarse contra el Gobierno, la Falange descabezada se había integrado, de facto, en el conjunto de fuerzas políticas derechistas que concurrían, desde una posición de subordinación táctica, en apoyo de la iniciativa de los militares. En los meses siguientes, FE-JONS se convirtió en una auténtica organización de masas y sus nutridas milicias desempeñaron un destacado papel en los frentes de guerra y en la brutal represión ejercida en la retaguardia. Pero sin José Antonio, fusilado en la prisión alicantina el 20 de noviembre, y con la Junta Política desmantelada, la estructura provisional de mando se vio sometida a los enfrentamientos entre sus posibles epígonos en la Jefatura nacional, que fueron incapaces de preservar la independencia de FE de las JONS cuando, en abril de 1937, el general Francisco Franco, en su papel de dictador militar, decretó la unificación de FE y de la Comunión Tradicionalista en un partido único -FET y de las JONS- que poco tenía que ver con la primera Falange y en el que el fascismo español tendría que ser reinventado a la conveniencia del flamante Caudillo y de su régimen ${ }^{37}$.

35 «Justificación de la violencia», en No Importa, $\mathrm{n}^{\circ}, 2,5-6-1936$.

36 J. A. Primo de Rivera, Obras completas, Madrid, Editora Nacional, 1976, vol. II p. 1012-1014.

37 Estudios fundamentales sobre el falangismo tras la Unificación son los de R. ChuECA Rodriguez, El fascismo en los comienzos del régimen de Franco. Un estudio sobre FET-JONS, Madrid, CIS, 1983, y J. M. Thом As, La Falange de Franco. El proyecto fascista del Régimen, Barcelona, Plaza \& Janés, 2001. 